\title{
Statistical Analysis of Modified Fading Simulator in Rayleigh Fading Environment
}

\author{
Arvind Dhaka $^{1 *}$ and Siddhartha Chauhan ${ }^{1}$ \\ ${ }^{1}$ CSE Department, NIT, Hamirpur, H.P., India \\ *arvind.neomatrix@gmail.com
}

\begin{abstract}
A real time communication system can be effectively analysed using Rayleigh fading channel. In this paper, we analyse and implement new filter sequence followed by inverse discrete Fourier transform for Rayleigh fading channel. A modified filtering sequence is proposed for Rayleigh fading channels. To validate the proposed model statistical properties like auto-correlation, cross-correlation of in-phase and quadrature components are compared with the desired one. Other simulation results like level crossing rate and average fade duration are shown in this paper as performance measure. In this paper bit error rate plot for Rayleigh fading channels is also analysed which shows improvement in the performance of Rayleigh fading channel.
\end{abstract}

Keywords: Rayleigh fading channels, Filtering sequence, Level crossing rate, Average fade duration, Doppler shift, Sum of Sinusoids model

\section{Introduction}

The analysis of Rayleigh fading channel is most commonly desired in the communication systems [1-4]. In this paper a method is proposed with modified filtering sequence for Rayleigh fading channel which is compared with new sum of sinusoids (SOS) model [5] and SOS uncorrelated model [6-8]. The mobile channels are usually different from wired channels, because of their randomness. The various frameworks have been proposed over the years for modeling and simulating the wireless channels [9-11]. The major problem of wireless channel is fading and the time dependency of the channel [9]. The signal frequency changes with time which makes the effect Doppler spread as time dependent [10-12]. The probability density function (PDF) of received envelope is shown to be Rayleigh [13]. Another form of the received wave is obtained in form of sinusoids which is useful in modeling sum of sinusoids model [12]. Over the years various SOS based fading channel simulators have been proposed [12, 13]. Basically, there is a great requirement to reduce the computational complexity of the simulator [13]. In the model proposed in this paper at least one of the parameters of the sinusoids is a random process and subsequently randomly-generated variable. The statistical properties of proposed model matched well with reference model which depict the accuracy proposed model. In this paper, a Rayleigh fading channel based on modified filtering sequence has been analysed and implemented. The Rayleigh fading channel has been implemented in the MATLAB programming language and simulation results have been obtained which governs the performance of proposed method.

The rest of the paper is organized as follows. Section 2 discusses proposed method. Section 3 details the performance measures. Results are discussed in Section 4. Finally, Section 5 concludes the work.

Received (December 15, 2017), Review Result (February 26, 2018), Accepted (March 5, 2018)

${ }^{*}$ Corresponding Author 


\section{The Proposed Algorithm}

In the proposed method doppler components are generated and then summed up to generate time domain envelope. However, there are various simulators like Smith's Simulator, Young's Simulator etc., [10] but this paper proposes an efficient Rayleigh Fading Simulator using modified filtering sequence. Using proposed technique a Rayleigh faded envelope is generated with specific statistical properties.

The proposed algorithm to generate modified filtering sequence for Rayleigh fading simulator is described below. In discrete fourier transform the negative sample lags is shifted by $2 \mathrm{~N}$ which specifies periodicity property of the autocorrelation sequence. After determining the various filter coefficients a zero mean complex Gaussian sequence is multiplied with generated filter coefficients and inverse discrete fourier transform (IDFT) operation is performed.

\section{Step 1: Calculation of Filter Coefficients}

The proposed model imposes the structure of filter $\mathrm{H}(\mathrm{f})$ and calculates filter coefficients. The filter transfer function in z-domain is represented as,

$$
\mathrm{H}(\mathrm{z})=\frac{1}{\mathrm{~A}_{\mathrm{k}}(\mathrm{z})}=\frac{1}{1+\sum_{\mathrm{k}=1}^{\mathrm{p}} \mathrm{a}_{\mathrm{k}} \mathrm{z}^{-1}}
$$

This equation can also be written as,

$$
y(n)=-\sum_{k=1}^{p} a_{k} x[n-k]+x(n)
$$

$a_{1}, a_{2}, a_{3} \ldots \ldots \ldots \ldots \ldots \ldots \ldots a_{k}$ are filter coefficients.

\section{Step 2: Autocorrelation Computation}

Autocorrelation is calculated for eq. 1a by using [14, eq. (10.8)] because computation becomes easy due to correlation matching property.

$$
\mathrm{AC}_{\mathrm{yy}}(\mathrm{k})= \begin{cases}-\sum_{\mathrm{N}=1}^{\mathrm{p}} \mathrm{a}_{\mathrm{N}} \mathrm{AC}_{\mathrm{yy}}[\mathrm{k}-\mathrm{N}], & \mathrm{k} \geq 1 \\ -\sum_{\mathrm{N}=1}^{\mathrm{p}} \mathrm{a}_{\mathrm{N}} \mathrm{AC}_{\mathrm{yy}}[\mathrm{k}-\mathrm{N}]+{\sigma_{\mathrm{N}}}^{2}, & \mathrm{k}=0\end{cases}
$$

$\sigma_{\mathrm{N}}^{2}$ is variance of noise. When number of sinusoids increases the accuracy of autocorrelation sequence also increases. For $\mathrm{k}=1,2 \ldots \mathrm{p}$ and the autocorrelation matrix form of eq. 2 becomes,

$$
\mathrm{AC}_{\mathrm{yy}}=\left[\begin{array}{ccccc}
\mathrm{AC}_{\mathrm{yy}}[0] & \mathrm{AC}_{\mathrm{yy}}[-1] & . . & . . & \mathrm{AC}_{\mathrm{yy}}[-\mathrm{p}+1] \\
\mathrm{AC}_{\mathrm{yy}}[1] & . & . . & . . & . . \\
. . & . & . . & . . & . . \\
\mathrm{AC}_{\mathrm{yy}}[\mathrm{p}-1] & \mathrm{AC}_{\mathrm{yy}}[\mathrm{p}-2] & . . & . . & \mathrm{AC}_{\mathrm{yy}}[0]
\end{array}\right]
$$

where $A=\left[\begin{array}{lllll}a_{1}, & a_{2}, & \ldots \ldots \ldots & a_{p}\end{array}\right]^{t}$,

$\mathrm{B}=\left[\begin{array}{llll}\mathrm{AC}_{\mathrm{yy}}[1], & \mathrm{AC}_{\mathrm{yy}}[2], & \ldots \ldots \ldots & \mathrm{AC}_{\mathrm{yy}}[\mathrm{p}]\end{array}\right]^{\mathrm{t}}$,

$\sigma_{\mathrm{N}}^{2}=\mathrm{AC}_{\mathrm{yy}}[0]+\sum_{\mathrm{k}=1}^{\mathrm{p}} \mathrm{AC}_{\mathrm{yy}}(\mathrm{k})$ and

$a_{N}=-\left(A C_{y y}+\xi I M\right)^{-1} B$. Here, IM is a identity matrix of size $p \times p$ and $\xi \neq 0$.

Remark 1: For fading signal $\mathrm{Z}(\mathrm{t})$ the statistical parameters are given by [12] which are,

$\mathrm{R}_{\mathrm{Z}_{\mathrm{c}} \mathrm{Z}_{\mathrm{c}}}(\tau)=\mathrm{J}_{0}\left(\omega_{\mathrm{d}} \tau\right), \mathrm{R}_{\mathrm{Z}_{\mathrm{s}} \mathrm{Z}_{\mathrm{s}}}(\tau)=\mathrm{J}_{0}\left(\omega_{\mathrm{d}} \tau\right), \mathrm{R}_{\mathrm{z}_{\mathrm{c}} \mathrm{Z}_{\mathrm{s}}}(\tau)=0, \mathrm{R}_{\mathrm{Z}_{\mathrm{s}} \mathrm{Z}_{\mathrm{c}}}(\tau)=0 \mathrm{R}_{\mathrm{ZZ}}(\tau)=$

$2 \mathrm{~J}_{0}\left(\omega_{\mathrm{d}} \tau\right), \mathrm{R}_{|\mathrm{Z}|^{2}|\mathrm{Z}|^{2}}(\tau)=4+4 \mathrm{~J}_{0}{ }^{2}\left(\omega_{\mathrm{d}} \tau\right)+\frac{2+\mathrm{J}_{0}\left(2 \omega_{\mathrm{d}} \tau\right)}{\mathrm{N}}$.

Remark 2: Using procedure given in [12] when $\mathrm{N}$ approaches infinity, the envelope $|\mathrm{Z}|$ is Rayleigh distributed and the phase $\psi(\mathrm{t})=\arctan \left[\mathrm{Z}_{\mathrm{c}}(\mathrm{t}), \mathrm{Z}_{\mathrm{s}}(\mathrm{t})\right]$ is uniformly distributed on $[-\pi, \pi]$. 


\section{Step 3: To Evaluate Impulse Response and Filter Taps}

Each filter coefficient must generate correlation fading channel tap. Assume, its impulse response is $\mathrm{FI}(\mathrm{k})$. The impulse response and filter taps are given in [11]. First order transform of $\mathrm{FI}(\mathrm{k})$ in s-domain is $\mathrm{FI}_{1}(\mathrm{~s})=\frac{\mathrm{p}_{\mathrm{x}}}{\mathrm{s}+\mathrm{p}_{\mathrm{x}}}$, second order transform is $\mathrm{FI}_{2}(\mathrm{~s})=\frac{\mathrm{p}_{\mathrm{x}}{ }^{2}}{\mathrm{~s}^{2}+\frac{\mathrm{p}_{\mathrm{x}} \mathrm{s}}{\mathrm{q}}+\mathrm{p}_{\mathrm{x}}^{2}}$. This can be generalized to higher order filter of order $\mathrm{n}$,

$$
\mathrm{FI}_{\mathrm{n}}(\mathrm{s})= \begin{cases}\mathrm{FI}_{2}^{\frac{\mathrm{n}}{2}}(\mathrm{~s}), & \mathrm{n}=\text { even } \\ \mathrm{FI}_{1}(\mathrm{~s}) \mathrm{FI}_{2}^{\frac{\mathrm{n}-1}{2}}(\mathrm{~s}), & \mathrm{n}=\text { odd }\end{cases}
$$

The value of $q$ is selected such that frequency response level at $p=p_{x} \mathrm{rad} / \mathrm{sec}$. This filter is generalized in z-domain,

$$
\mathrm{FI}_{\mathrm{n}}(\mathrm{z})=\frac{\sum_{\mathrm{k}=0}^{\mathrm{n}} \mathrm{FI}_{\mathrm{k}}^{\mathrm{M}} \mathrm{z}^{-\mathrm{k}}}{1-\sum_{\mathrm{k}=1}^{\mathrm{n}} \mathrm{FI}_{\mathrm{k}}^{\mathrm{A}} \mathrm{z}^{-\mathrm{k}}}
$$

Here, $\left\{\mathrm{FI}_{\mathrm{k}}^{\mathrm{A}}\right\}_{\mathrm{k}=1}^{\mathrm{n}}$ and $\left\{\mathrm{FI}_{\mathrm{k}}^{\mathrm{M}}\right\}_{\mathrm{k}=0}^{\mathrm{n}}$ form filter taps.

\section{Step 4: Calculation of Magnitude and Phase Part}

Now we calculate magnitude and phase components for the impulse response by differentiating $\mathrm{FI}_{\mathrm{n}}(\mathrm{z})$, w.r.t $\mathrm{x}$ and $\mathrm{e}^{\mathrm{jw}}$ from eq. 5, with $\theta, \psi$ being a random variable uniformly distributed on $[-\pi, \pi]$

For zeros the magnitude part is given as,

$$
\frac{\delta \mathrm{FI}^{\mathrm{M}}\left(\mathrm{x}, \mathrm{e}^{\mathrm{jw}}\right)}{\delta \mathrm{x}_{\mathrm{n}}}=\left|\mathrm{FI}^{\mathrm{M}}\left(\mathrm{x}, \mathrm{e}^{\mathrm{jw}}\right)\right| \frac{\mathrm{x}(\mathrm{n})-\cos \left(\theta_{\mathrm{k}}-\omega\right)}{\left|1-\mathrm{x}(\mathrm{n}) \mathrm{e}^{\mathrm{j}\left(\theta_{\mathrm{k}}-\omega\right)}\right|^{2}}
$$

For zeros the phase part is given as,

$\frac{\delta \mathrm{FI}^{\mathrm{M}}\left(\mathrm{x}, \mathrm{e}^{\mathrm{j} w}\right)}{\delta \varphi_{\mathrm{n}}}=\left|\mathrm{FI}^{\mathrm{M}}\left(\mathrm{x}, \mathrm{e}^{\mathrm{j} w}\right)\right| \frac{\mathrm{x}(\mathrm{n}) \cdot \sin \left(\theta_{\mathrm{k}}-\mathrm{w}\right)}{\left|1-\mathrm{x}(\mathrm{n}) \mathrm{e}^{\mathrm{j}\left(\theta_{\mathrm{k}}-\mathrm{w}\right)}\right|^{2}}$

For poles the magnitude part is given as,

$\frac{\delta \mathrm{FI}^{\mathrm{A}}\left(\mathrm{x}, \mathrm{e}^{\mathrm{jw}}\right)}{\delta \mathrm{x}_{\mathrm{n}}}=\left|\mathrm{FI}^{\mathrm{A}}\left(\mathrm{x}, \mathrm{e}^{\mathrm{j} \mathrm{w}}\right)\right| \frac{\cos \left(\theta_{\mathrm{k}}-\mathrm{w}\right)-\mathrm{x}(\mathrm{n})}{\left|1-\mathrm{x}(\mathrm{n}) \mathrm{e}^{\mathrm{j}\left(\theta_{\mathrm{k}}-\mathrm{w}\right)}\right|^{2}}$

For poles the phase part is given as,

$\frac{\delta \mathrm{FI}^{\mathrm{A}}\left(\mathrm{x}, \mathrm{e}^{\mathrm{jw}}\right)}{\delta \varphi_{\mathrm{n}}}=\left|\mathrm{FI}^{\mathrm{A}}\left(\mathrm{x}, \mathrm{e}^{\mathrm{jw}}\right)\right| \frac{-\mathrm{x}(\mathrm{n}) \cdot \sin \left(\theta_{\mathrm{k}}-\mathrm{w}\right)}{\left|1-\mathrm{x}(\mathrm{n}) \mathrm{e}^{\mathrm{j}\left(\theta_{\mathrm{k}}-\mathrm{w}\right)}\right|^{2}}$

\section{Step 5: Representation in Terms of Sinusoids and Cosine Terms and Extraction of Zero and Non-zero Samples}

Based on observation of [15, eqs. (5a-5f)] and by keeping non-zero values of samples for impulse response, the Rayleigh fading process can be expressed in terms of in-phase and quadrature components. To represent as sinusoids and cosine terms partial derivatives are computed for our proposed filtering sequence by keeping non-zero values of samples as given in eq. $9 \mathrm{a}$. A gradient vector $(V)$ is calculated by differentiating $y(n)$ from eq. $1 b$ w.r.t $A_{k}$ and $x(n)$. This equation becomes,

$$
\mathrm{V}\left(\mathrm{A}_{\mathrm{k}}, \mathrm{x}(\mathrm{n})\right)=\left[\frac{\delta \mathrm{y}\left(\mathrm{A}_{\mathrm{k}}, \mathrm{x}(\mathrm{n})\right)}{\delta \mathrm{x}_{1}}, \ldots \ldots \ldots \ldots . . \frac{\delta \mathrm{y}\left(\mathrm{A}_{\mathrm{k}}, \mathrm{x}(\mathrm{n})\right)}{\delta \mathrm{x}_{\mathrm{n}}}\right]
$$

Partial derivative of $\mathrm{y}\left(\mathrm{A}_{\mathrm{k}}, \mathrm{x}(\mathrm{n})\right)$ w.r.t. $\mathrm{n}^{\text {th }}$ component of $\mathrm{x}(\mathrm{n})$ are calculated for nonzero and zero samples as, 


$$
\mathrm{y}_{\mathrm{i}}^{\mathrm{n}}=\frac{\delta \mathrm{y}\left(\mathrm{A}_{\mathrm{k}}, \mathrm{x}(\mathrm{n})\right)}{\delta \mathrm{x}_{\mathrm{n}}}
$$

For non-zero samples,

$$
y_{i}^{n}=\sum_{i=0}^{n} \frac{\left(A_{i} \log \mid\left(F I\left(x, e^{j w_{i}}\right)|-\log |\left(y_{i}^{n}\right)^{2} \mid\right)\right.}{\mid\left(F I\left(x, e^{j w_{i}}\right) \mid\right.} \cdot \frac{\delta F I\left(x, x, e^{j w_{i}}\right)}{\delta x_{n}}
$$

For zero samples,

$$
\mathrm{y}_{\mathrm{i}}^{\mathrm{n}}=\mathrm{k}
$$

\section{Step 6: Computation of IDFT}

IDFT is then taken for this complex sequence to form the complex time sequence [16, eq. 12]. The SOS methods [5] and [6] requires longer simulation time as compared to proposed method as the number of sinusoids $M$ is small.

\section{Performance Measures}

Two important second order statistics associated with envelope fading LCR and AFD for a specified level $R$ would be computed in the following section. The generic expression for the AFD for a fade below a level of $R \mathrm{~dB}$ is given by Kantas. A. et. al., [17].

\section{Calculation of LCR}

LCR of a stationary random process $r(t)$ at level $\mathrm{R}$ is given by $N_{R}=$ $\int_{0}^{\infty} \dot{r} p_{r, \dot{r}}(R, \dot{r}) d \dot{r}[12]$.

Dot indicates time derivative i.e., $\dot{r}=\frac{d r}{d t}$ and $p_{r, \dot{r}}(R, \dot{r})$ is joint density function of $r$ and $\dot{r}$ at $r=R$. Rice [18] gave joint density function of four random variables, $r, \dot{r}, \theta, \dot{\theta}$ of a Gaussian process as,

$$
p(r, \dot{r}, \theta, \dot{\theta})=\frac{r^{2}}{4 \pi^{2} b_{0} b_{2}} \exp \left[-\frac{1}{2}\left(\frac{r^{2}}{b_{0}}+\frac{\dot{r}^{2}}{b_{2}}+\frac{r^{2} \dot{\theta}^{2}}{b_{2}}\right)\right]
$$

where $\infty$ is argument angle of complex signal.

For Rayleigh faded Envelope joint density function $p_{\dot{r}_{1}}$ and $p_{\dot{r}_{2}}$ are known as [12, 19],

In order to derive LCR for Rayleigh faded Envelope integrate eq. 10 with $\theta$ from 0 to $2 \pi$ and $\dot{\theta}$ from $-\infty$ to $\infty$. LCR can be written as,

$N_{R}=\frac{p(R)}{\sqrt{2 \pi b_{2}}} \int_{0}^{\infty} \dot{r} e^{-\frac{\dot{r}^{2}}{2 b_{2}}} d \dot{r}$

Here, $b_{2}$ is second moment of spectrum of channel $h_{1}$ and $h_{2}$ respectively, such that $r_{1} r_{2}=r=\left|h_{1} h_{2}\right|$, which can be verified using autocorrelation function of $h_{1}$ and $h_{2}$. Envelope of $r_{i}$ is independent and uncorrelated to $\dot{r}_{i}$ where, $h_{1}=x_{1}+j y_{1}$ and $h_{2}=$ $x_{2}+j y_{2}[19]$. $x$ and $y$ denotes magnitude and phase component of $h$.

\section{Calculation of AFD}

As proposed by Rice [18], we can write density function of Rayleigh channel as in terms of $r$ as $p(r)=\frac{r}{b_{0}} e^{\frac{-r^{2}}{2 b_{0}}}$. Now, calculate $C D F$ of density function $p(r)$ by integrating it.

$$
P(r)=\int_{0}^{\infty} \frac{r}{b_{0}} e^{\frac{-r^{2}}{2 b_{0}}} d r
$$


Simplifying eq. 12 results in,

$$
P(r)=1-e^{\frac{-r^{2}}{2 b_{0}}}
$$

Average fade duration is written as, $A F D=\frac{P(r)}{N_{R}}$. Therefore,

$$
A F D=\sqrt{\frac{2 \pi}{b_{o}}}\left(\frac{e^{\frac{r^{2}}{2 b_{0}}}-1}{r}\right)
$$

If fading is extremely slow, the effects on the output signal received may not be too bad. As fading rate increases even above $1 \mathrm{~Hz}$, it becomes important to take care of it. We have considered the case of different Doppler Frequency of $10 \mathrm{~Hz}$ to $200 \mathrm{~Hz}$.

\section{Results and Discussions}

In this paper, we have used the MATLAB communication toolbox to evaluate the performance of proposed modified filtering sequence in Rayleigh fading environment. We have used $f_{d}=100 \mathrm{~Hz}$, normalized $f_{d} \tau=1 \times 10^{-4}$ for 500 samples. Using the proposed method the output envelope is observed. It has been found that obtained envelope of the output sequence is similar to the envelope obtained using an ideal filter. Figure 1 plots signal envelope in time domain for $f_{d}=100 \mathrm{~Hz}, \mathrm{t}=0.05 \mathrm{sec}$ generating 500 samples. Figure 2 shows time domain comparison plot for magnitude of received signal at multiple Doppler frequencies where five different vales of $f_{d}$ is taken as 10, 50, 100, 150, $200 \mathrm{~Hz}$. $f_{d} \tau$ varies from $1 \times 10^{-6}$ to $2 \times 10^{-4}$. Bit error rate (BER) has been obtained and based on the results obtained in this paper, where signal to noise ratio is $10 \log 10 \frac{E_{b}}{2 N_{0}}=\frac{E_{b}}{\sigma^{2}}, E_{b}$ is the energy per bit, and $\sigma$ is the standard deviation of noise and $N_{0}$ is the noise Power Spectral Density (PSD). Figure 3 shows comparison of BER from uncorrelated SOS model [5] where $f_{d} \tau=1 \times 10^{-4}$ from eq. 13 generating maximum 500 samples with $f_{d}=100 \mathrm{~Hz}$, from New SOS model [6] and proposed method generating maximum 500 samples with $f_{d}=100 \mathrm{~Hz}, M=\frac{N}{4}, \phi=\frac{\pi}{4}$. Root mean square (RMS) value calculated for received signal simulated using proposed method for $f_{d}=100 \mathrm{~Hz}$ is shown in Figure 4(a). Plot showing PDF of phase component calculated from proposed method is given in Figure 4(b). For our simulation we have calculated all the fades that cross the reference value in the negative direction. The range of the reference values that we have considered in the simulations varies from $-40 \mathrm{~dB}$ to $+20 \mathrm{~dB}$ from the mean square value. Figure $5(\mathrm{a})$, 5(b) and 5(c) compares the LCR, AFD and RMS value respectively. 


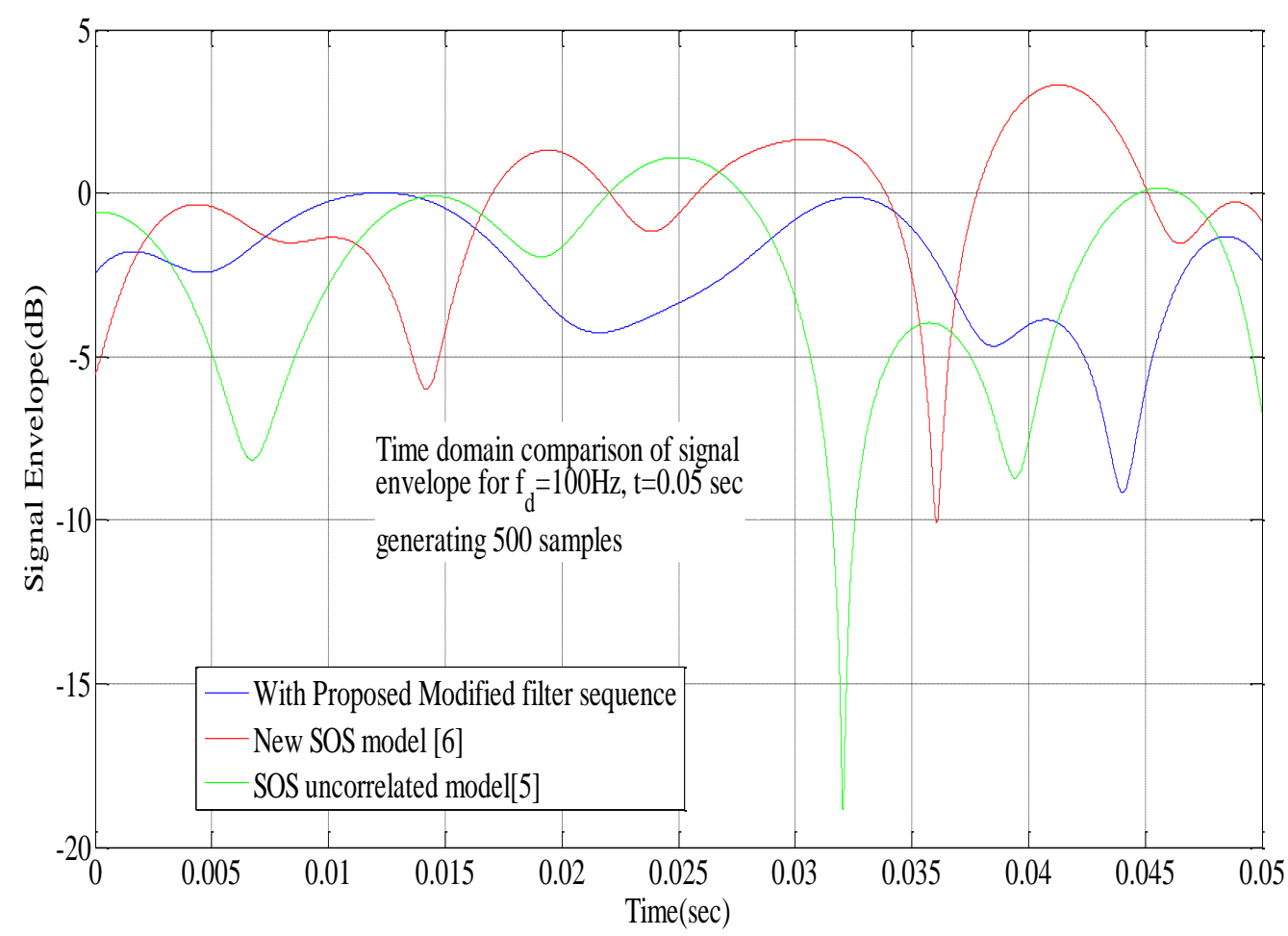

Figure 1. Plot of Signal Envelope in Time Domain

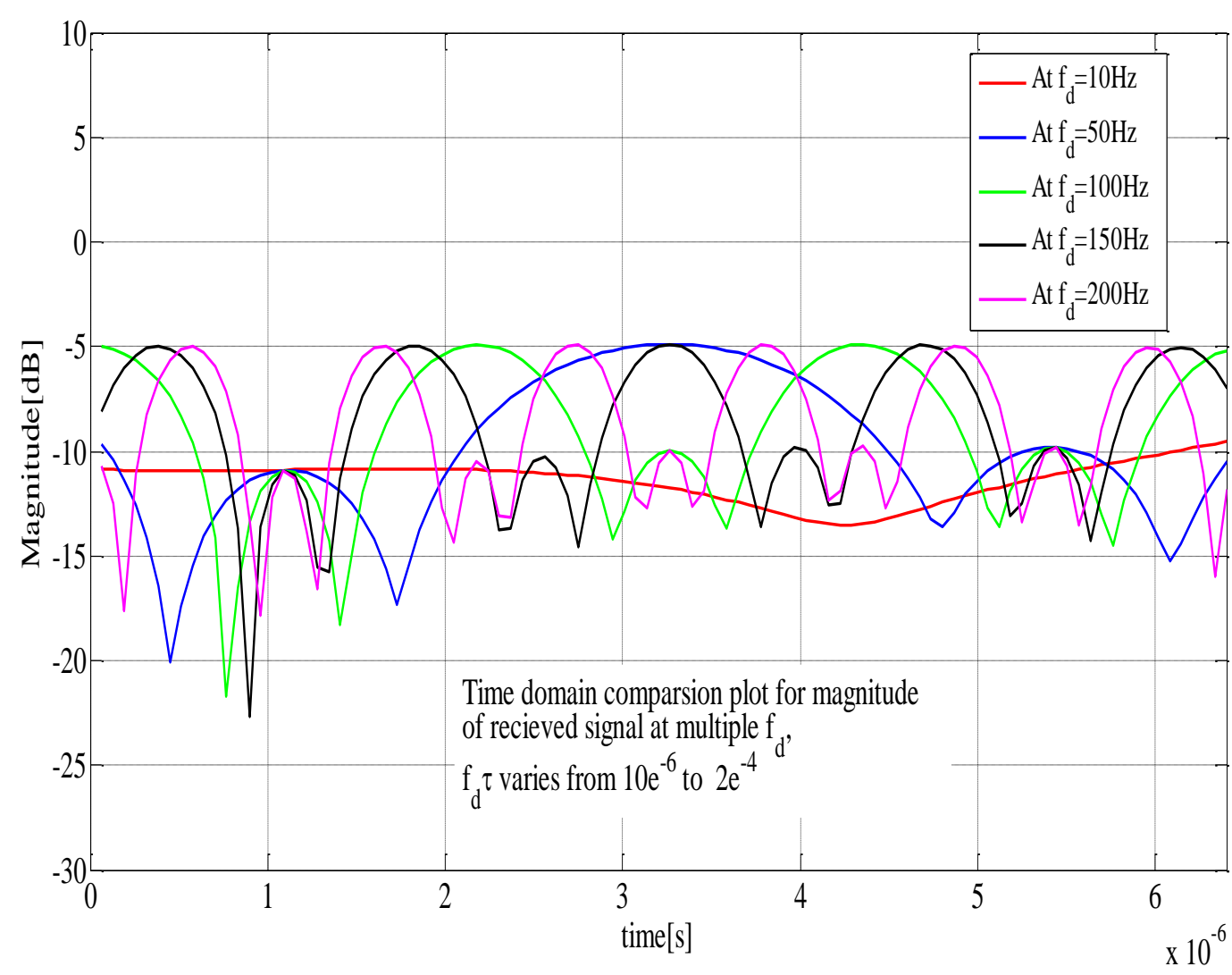

Figure 2. Time Domain Comparison using Proposed Method 


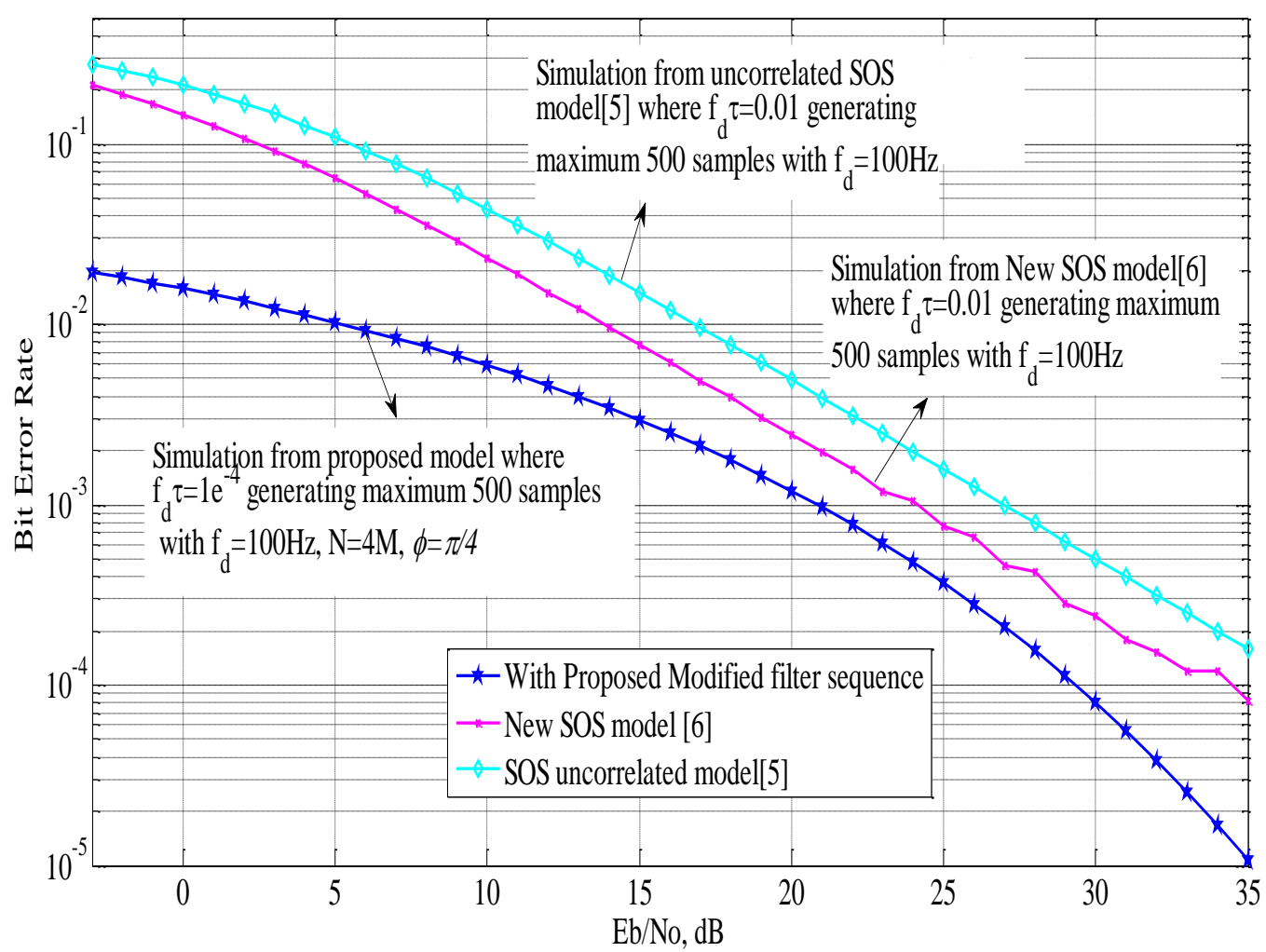

Figure 3. BER Plot using Different Methods in Rayleigh Channel

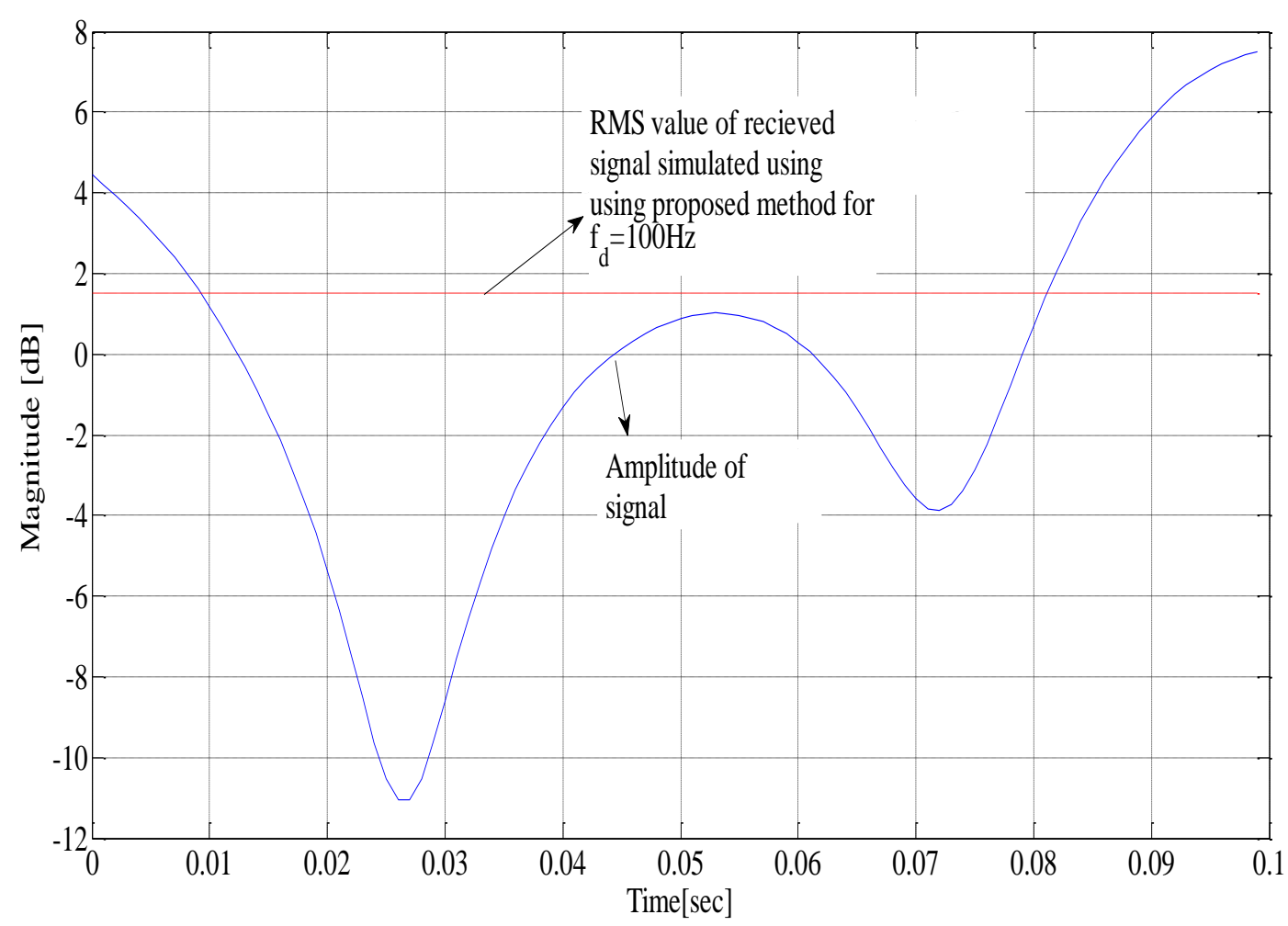

(a) 


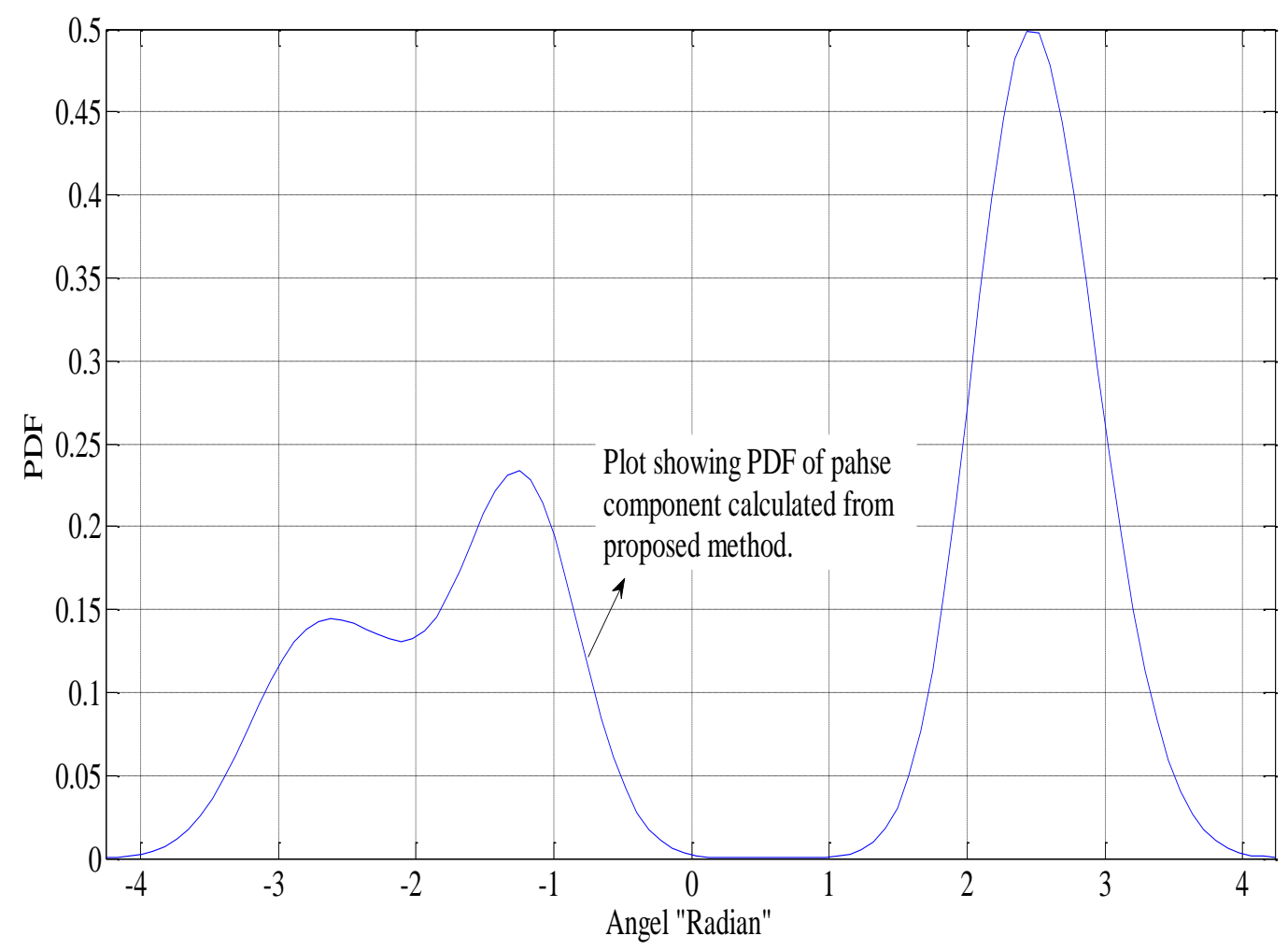

(b)

Figure 4. (a) RMS Value of Received Signal (b) PDF of Phase Component

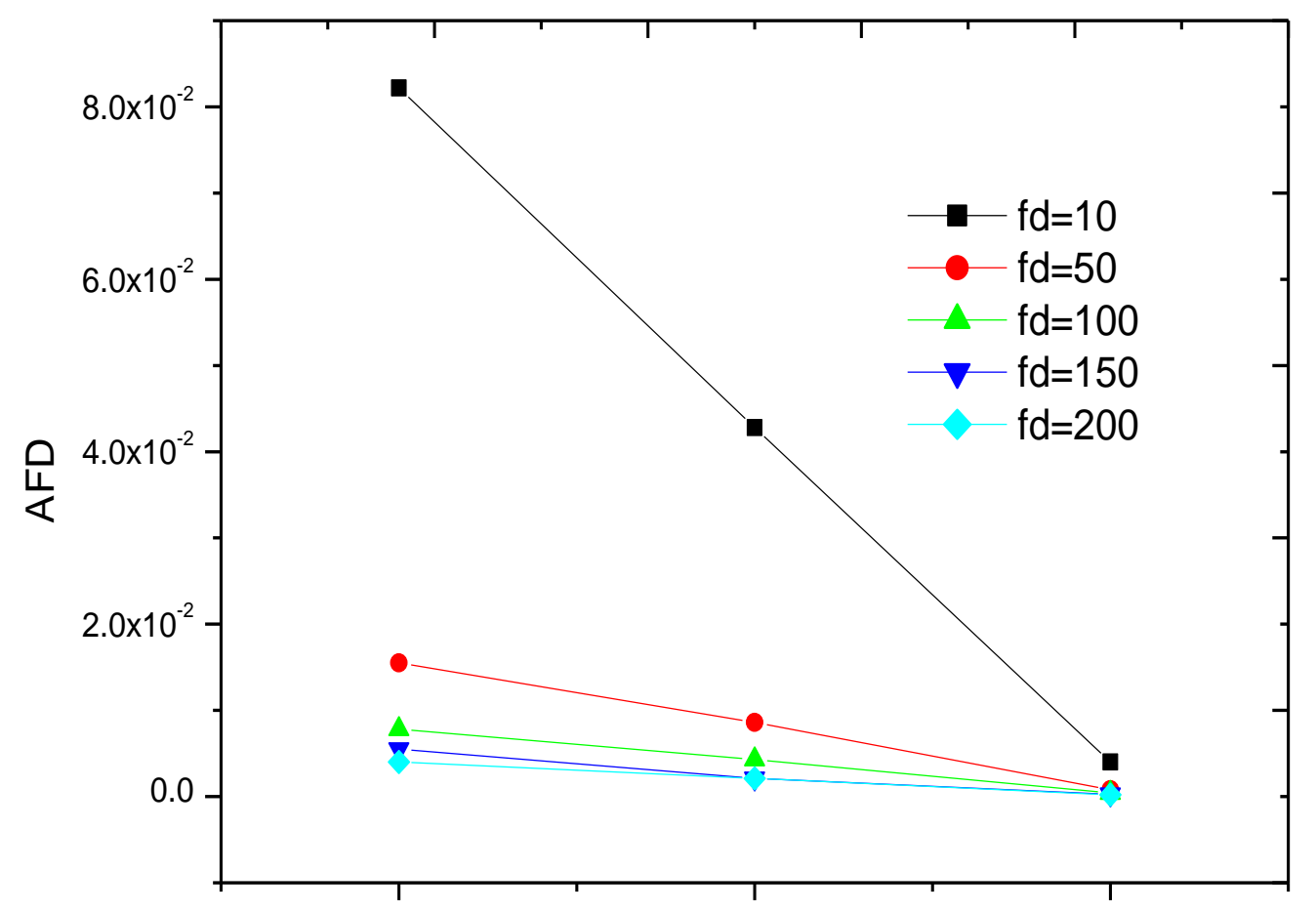

New SOS model [5] SOS uncorrelated model [6] Proposed model

(a) AFD Comparison 


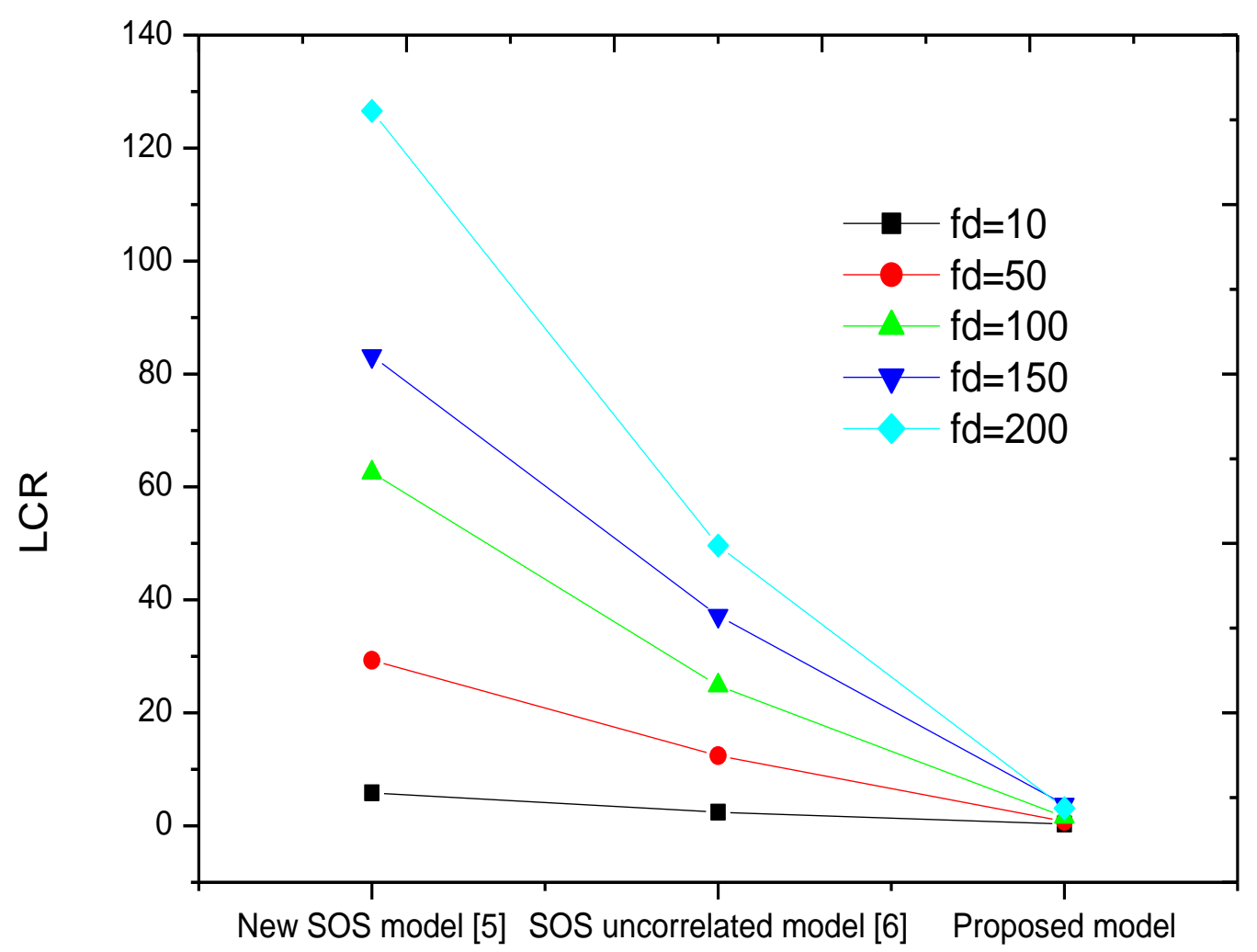

(b) LCR Comparison

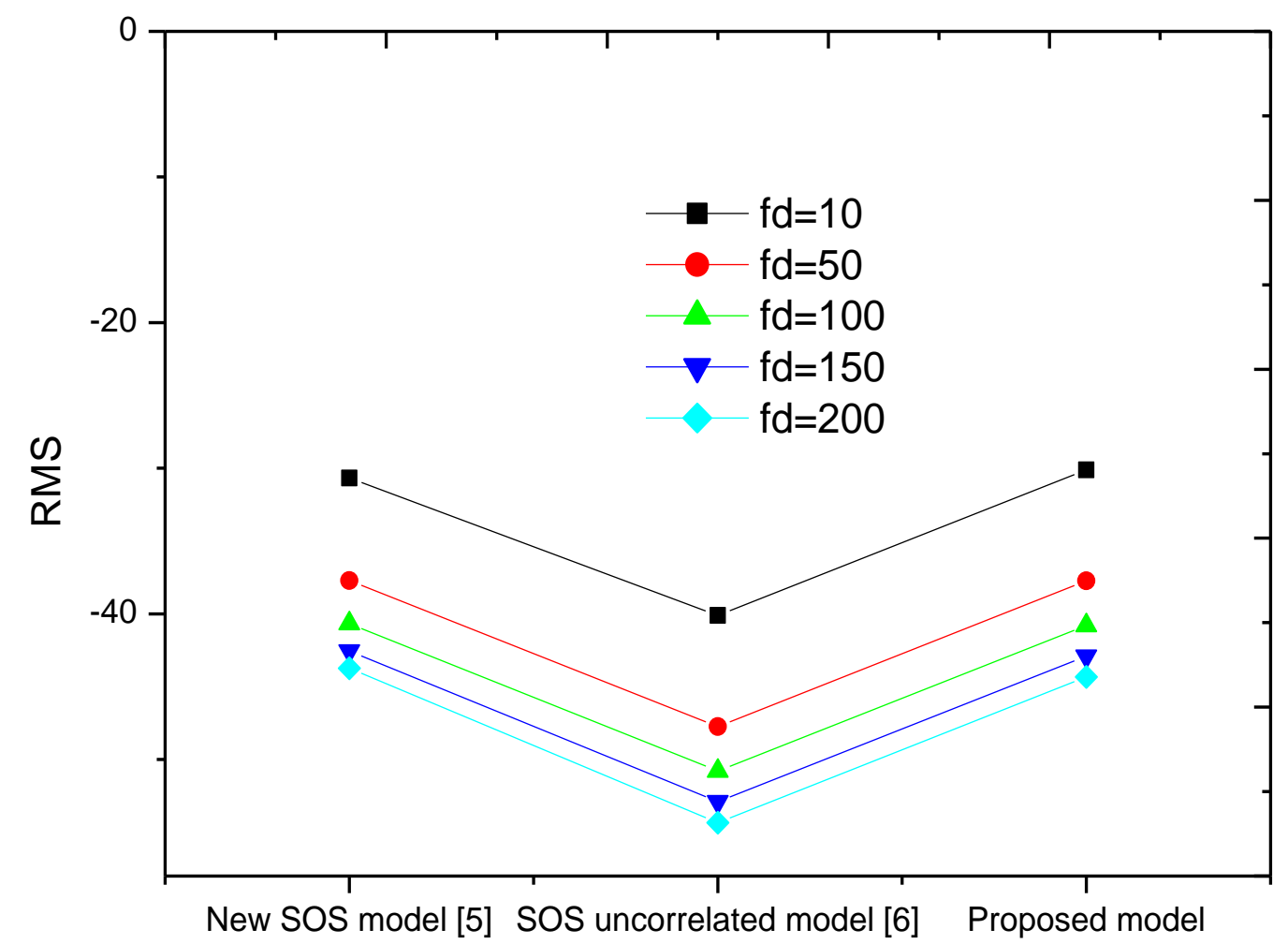

(c) RMS Comparison

Figure 5. Comparison Plots for Various Performance Measures 


\section{Conclusion and Future Work}

In this paper, a modified filtering sequence is used to calculate Doppler components and then summed up to generate time domain envelope. The overall channel transfer function has a frequency response whose characteristics are finally expressed in terms of sinusoids and cosines. Various parameters such as, LCR, AFD, BER and root mean square value are compared for accuracy and performance of proposed Rayleigh fading simulator with the techniques reported in literature Doppler frequency of $10 \mathrm{~Hz}$ to $200 \mathrm{~Hz}$. For more accuracy, the number of samples can be increased and as future work can be effectively used in simulating various wireless communication systems related applications.

\section{References}

[1] C. D. Iskander, "A MATLAB Based Object-oriented Approach to Multipath Fading Channel Simulation", Hi-Tek Multisystems White paper, Quebec, Canada, (2008).

[2] B. Sklar, "Rayleigh Fading Channels in Mobile Digital Communication System Part 1: Characterisation”, IEEE Communication Magazine, vol. 35, no. 7, (1997), pp. 90-100.

[3] Z. K. Adeyemo, and T. I. Raji, "Bit Error Rate Analysis for Wireless Links Using Adaptive Combining Diversity", Journal of Theoretical and Applied Information Technology, vol. 20, no. 1, (2010), pp. 5866.

[4] M. S. Alouini, T. Xiaoyi and A. J. Goldsmith, "An Adaptive Modulation Scheme for Simultaneous Voice and Data Transmission over Fading Channels", IEEE Journal on Selected Areas in Communications, vol. 17, no. 5, (1999), pp. 837-847.

[5] Y. Gan and Y. Wu, "Multiple Rayleigh fading channels modelling based on sum-of-sinusoids model", International Journal of Communication Systems, vol. 27, no. 11, (2014), pp. 2997-3012.

[6] Y. R. Zheng, and C. Xiao, "Improved models for the generation of multiple uncorrelated Rayleigh fading waveforms", IEEE Communication Letters, vol. 6, no. 6, (2002), pp. 256-258.

[7] D. Xuanming, "Effect of Slow Fading and Adaptive Modulation on TCP (UDP) Performance of Highspeed packet Wireless Networks", Technical Report, No. UCB/EECS-2006- 109, University of California, Berkeley, (2006).

[8] W. Steven, G. A. Jeffrey and J. Nihar, "The Effect of Fading, Channel Inversion, and Threshold Scheduling on Ad Hoc Networks", IEEE Transmissions on Information Theory, vol. 53, no. 11, (2007), pp. 4127-4149.

[9] S. Parastoo, and R. Predrag, "On Information Rate of Time-varying Fading Channels Modelled as Finite-State Markov Channels", IEEE Transactions on Communication, vol. 56, no. 8, (2008), pp. 12681278.

[10] M. Pätzold, "Mobile Fading Channels", West Sussex, U.K., Wiley, (2002).

[11] T. S. Rappaport, "Wireless Communications: Principles and Practice", 2nd Edition, Prentice Hall, (2007).

[12] G. L. Stüber, "Principles of Mobile Communication", New York: Kluwer Academic Publishers, Norwell, MA, 2nd Edition, (2001).

[13] C. Xiao, Y. R. Zheng and N. C. Beaulieu, "Novel sum-of sinusoids simulation models for Rayleigh and Rician fading channels", IEEE Transactions on Wireless Communication, vol. 5, no. 12, (2006), pp. 3667-3679.

[14] A. Papoulis, "Probability, Random Variables, and Stochastic Processes", 3rd ed., McGraw-Hill, Toronto, (1991).

[15] C. Xiao, Y. R. Zheng and N. C. Beaulieu, "Second-order statistical properties of the WSS Jakes' fading channel simulator", IEEE Transactions on Communication, vol. 50, no. 6, (2002), pp. 888-891.

[16] A. Arsal and S. R. Ozen, "A fading filter design for multipath Rayleigh fading simulation and comparisons to other simulators", IEEE $19^{\text {th }}$ International Symposium on Personal, Indoor and Mobile Radio Communications, vol. 50, (2002), pp. 888-891.

[17] A. Kantas, N. Papadakis, P. Chatzopoulos, T. Sofos and P. Constantinou, "Land-Mobile Satellite Channel Measurements in Athens City Center at $1800 \mathrm{Mh}$ ", International Mobile Satellite Conference, (1997), pp. 169-175.

[18] S. O. Rice, "Mathematical Analysis of Random Noise", Bell System Technical Journal, vol. 23, no. 3, (1994), pp. 282-332.

[19] A. S. Akki, and F. Haber, "A statistical model for mobile-to-mobile land communication channel”, IEEE Transactions on Vehicular Technology, vol. 35, no. 1, (1986), pp. 2-7. 


\section{Authors}

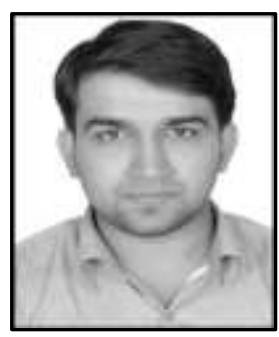

Arvind Dhaka received his Master's degree in Computer Science Engineering from Central University of Rajasthan, Ajmer, India and Bachelor's Degree from Govt. Engineering College, Bikaner, India. Currently, he is working towards his Ph.D. degree from NIT Hamirpur in Department of Computer Science and Engineering. His research interests include Wireless Communication, Wireless Sensor Networks, Ad-Hoc Networks, Image Processing, Cryptography and Network Security. Previously, he also worked at NIT Hamirpur as Assistant Professor.

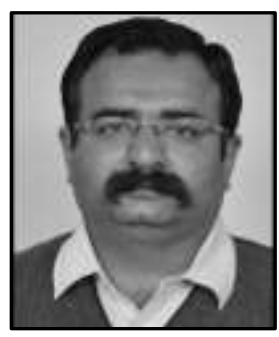

Dr. Siddhartha Chauhan received the Ph.D. degree in computer science and engineering from National Institute of Technology Hamirpur, Himachal Pradesh, India, in 2013 and the M.Tech. degree in computer science and engineering from Indian Institute of Technology, Roorkee, Uttrakhand, India, in 2003. He has published many research papers in international conferences and journal. He is currently with Department of Computer Science and Engineering, National Institute of Technology, Hamirpur, Himachal Pradesh, India. His research interests include mobile ad hoc network and wireless sensor network. 
International Journal of Grid and Distributed Computing

Vol. 11, No. 4 (2018) 